\title{
POST DURAL PUNCTURE HEADACHE AFTER ELECTIVE CAESAREAN SECTION USING 27 G QUINCKE AND WHITACRE SPINAL NEEDLES: A COMPARATIVE STUDY
}

\author{
Pawan Puspa Baral, ${ }^{1}$ Laxmi Pathak, ${ }^{1}$ Rejin Kumar Udaya, ${ }^{1}$ Anita Lawoju, ${ }^{2}$ Sita Pokhrel, ${ }^{1}$ Pramod Kumar Gupta ${ }^{1}$
}

\begin{abstract}
INTRODUCTION

Post-dural puncture headache (PDPH), a serious complication of spinal anesthesia (SA) may persevere for long time and can be unbearable to the patients. The incidence of PDPH unswervingly relies on the size of the spinal needles used and this gradually decreases with the use of thinner spinal needles. This study was designed to study the more reliable $27-\mathrm{G}$ $(0.41 \mathrm{~mm})$ Whitacre and Quincke spinal needles, equating the frequency of PDPH in combination with spinal anesthesia after elective cesarean section.
\end{abstract}

\section{MATERIAL AND METHODS}

A prospective randomized single blinded study was conducted during the period between 1 to 29 January 2019, at Universal College of Medical Sciences, Nepal. A total of 120 patients (between 20-35 years of age) were divided into two groups: Group I: 60 patients given SA with 27-G Quincke needle and Group II: 60 patients given SA with 27-G Whitacre needle. Randomization was done by coin tossing method and double-blinded except for the anesthetist performing the spinal block. Patients were interviewed on days 1 to 5 and were questioned with regard to headache based on its severity, location, character, duration, associated symptoms (nausea, vomiting, auditory and ocular symptoms). The severity of the headache was analyzed by Crocker scale.

\section{RESULTS}

The results showed that $33 \%$ more headache in group A, but the t-value was 0.727 and $p$-value was 0.2345 which was statistically insignificant.

\section{CONCLUSION}

Hence, using 27-G Whitacre spinal needles are shown to be clearly associated with fewer cases of PDPH.

\section{KEYWORDS}

Cerebrospinal fluid, Post-dural puncture headache, Spinal anesthesia.

1. Department of Anesthesia, Universal College of Medical Sciences, Bhairahawa, Nepal

2. Department of Anesthesia, Lumbini Eye Institute, Bhairahawa, Nepal

DOI: http//doi.org/10.3126/jucms.v9i01.37842

\author{
For Correspondence \\ Dr. Pawan Puspa Baral \\ Department of Anesthesia \\ Universal College of Medical Sciences \\ Bhairahawa, Nepal \\ Email: pawonbrl.dr@gmail.com
}




\section{INTRODUCTION}

In cesarean section, it is well established that general anesthesia is correlated with comparatively more maternal risk than regional anesthesia. Spinal anesthesia (SA) (familiarized in clinical practice by August Bier in 1898), is the most commonly performed anesthetic technique encompassing factors like easy execution method, swift result and admirable operating conditions. ${ }^{1}$ Certain advantages of this technique entails its simplicity, minimal armamentarium and drugs, safeguards optimum blood biochemistry and arterial blood gas levels, conscious status of patients, airway evasion, good post-operative analgesia. ${ }^{2}$

Post-dural puncture headache (PDPH) is a well-distinguished impediment of SA, particularly in younger patients. It may persevere for few hours or weeks, may be temporary and selflimiting occasionally, can be unendurable resulting in persistent hospital stay and magnified cost. ${ }^{3}$ PDPH probably arises as an expected difficulty of lumbar puncture, with indications connected to traction on pain-sensitive structures from low cerebrospinal fluid (CSF) pressure (intracranial hypotension) following CSF leak at the puncture site. ${ }^{4}$ The frequency and severity of PDPH is thought to be influenced by patient's age and size of the dural perforation. Its occurrence directly depends on the size of the spinal needles applied and gradually decreases to thinner ones (like Quincke-type cutting needles), and shows less correlation with Whitacre-type noncutting spinal needles. It is established that even with a thicker $25-\mathrm{G}(0.5 \mathrm{~mm})$ Whitacre spinal needle the frequency of PDPH is ominously lesser than a thinner $27-\mathrm{G}(0.41 \mathrm{~mm})$ Quincke spinal needle. ${ }^{5}$ Quincke, Whitacre and Sprotte types are the three basic needle points available. Quincke point is a simple cutting needle like the common venipuncture needle. The tapered "pencil-point" tip with lateral displacement of the distal orifice of the Whitacre intends to bring about an atraumatic splitting of the dural fibers rather than the cutting action of the Quincke.

It is however, advised that an optimal spinal needle should trigger PDPH infrequently, so that the clinician can recognize the intrathecal space precisely and can inject the LA into the subarachnoid space carefully. It has been seen that extremely thin, 29-G spinal needles are precisely challenging to use since the flow of spinal fluid representing the exact location of needle tip is extremely slow and the needle might be unintentionally relocated during the injection of the LA. ${ }^{7}$ Therefore, this study was designed to study the more reliable $27-\mathrm{G}(0.41 \mathrm{~mm})$ Whitacre and Quincke spinal needles, equating the frequency of PDPH in combination with spinal anesthesia after elective cesarean section.

\section{MATERIAL AND METHODS}

A prospective randomized single blinded study was conducted between 1 to 29 January 2019, in the Department of Gynecology and Obstetrics, at Universal College of Medical Sciences, Nepal, after approval from IRB. Exclusion criteria included patients having fetal distress, toxemia of pregnancy, CVS/CNS or neuromuscular diseases, hypovolemia, acid base and electrolyte imbalance, obesity, infection on the back, anticoagulant therapy, vertebral anomaly, more than two attempts of failed or inadequate spinal anesthesia.

A total of 120 patients (within 20-35 years of age) who were eligible for elective $\mathrm{C}$-section were randomly divided into two groups: Group I: 60 patients given SA with 27-G Quincke needle and Group II: 60 patients given SA with 27-G Whitacre. Randomization was done by coin tossing method and double-blind except for the anesthetist performing the spinal block. The patients, surgeons, anesthesiologist and PACU as well as the post-operative ward people were unaware of the spinal needle to be used. A thorough medical and past history of anesthetic exposure, history of drugs taken in preoperative period was recorded. General and systemic examinations, routine investigation including coagulation profile was done. Inj. Ranitidine $150 \mathrm{mg}$ IV and Inj. Metoclopramide $10 \mathrm{mg}$ were given preoperatively one hour before surgery and each patient was continuously monitored and baseline readings were noted. All procedures were performed in sitting position by same anesthesiologist. SA was performed using a midline approach at the L2-3 or L3-4 interspace using one of the above spinal needles and $0.5 \%$ hyperbaric bupivacaine 2.5-3.0 $\mathrm{ml}$ was injected. After withdrawal of the needle, the patient was turned to the supine position with left uterine displacement. Level of sensory blockade and changes in parameters like heart rate, BP were recorded. Solution of Ringer lactate, colloid and blood was transfused as maintenance fluid. Complications like nausea, vomiting, bradycardia, respiratory depression, skin reactions were managed symptomatically. Patients were interviewed on day 1,2, 3, 4, 5- with regard to headache: its severity, location, character, duration, associated symptoms like nausea, vomiting, auditory and ocular symptoms.

\section{The criteria for PDPH were:}

a) Occurred after mobilization.

b) Mostly frontal and occipital in distribution.

c) Exaggerated within 15 minutes of standing, sitting, straining and relieved within 15 minutes lying flat.

d) Associated with nausea or vomiting

The severity of the headache was analyzed by Crocker scale (1976) and given a score between 1-4 as under.

\section{GRADE /SCORE SYMPTOMS}

1. Mild headache allowing long periods of sitting: no associated nausea or vomiting

2. Moderate headaches which made sitting difficult ( $>$ half an hour):occasionally associated with nausea, vomiting

3. Severe headaches which made sitting difficult frequently; associated with nausea, vomiting

4. Intense headaches even in lying down; nausea and vomiting with impossible feeding

The typical features of headache were described with respect 
to: onset, location, quality aggravating and relieving factor, duration, associated symptoms (vertigo, nausea, vomiting, blurring of vision and neck rigidity).

These questions were asked twice daily to all patients. The PDPH was treated conservatively with bed rest, hydration, and paracetamol $15 \mathrm{mg} / \mathrm{kg}$ orally four times daily and advising coffee intake.

\section{RESULTS}

Out of 120 patients, Group A (27G Quincke) patients had a mean age of 25.46 years (17-42 years) whereas, in group B (27 $\mathrm{G}$ Whitacre) mean age was 26.3 years (18-36 years) (Figure 1). The incidence of headache after anaesthesia between both the groups is shown in Table 1. In Group A, 27 and 33 patients and in Group B, 21 and 39 were primiparous and multiparous respectively.

Although the result reported that $33 \%$ more headache in group $\mathrm{A}$, but the t-value was 0.727 and $p$-value was 0.2345 which was statistically insignificant. Further age-wise distribution of headache showed that in Group A, all the four patients within 26 to 30 years, while one other patient was below 25 years of age. In group B, two patients each were below 25 and 26-30 age group. Table 2 illustrated the location, type, duration and onset of headache in different age regions.

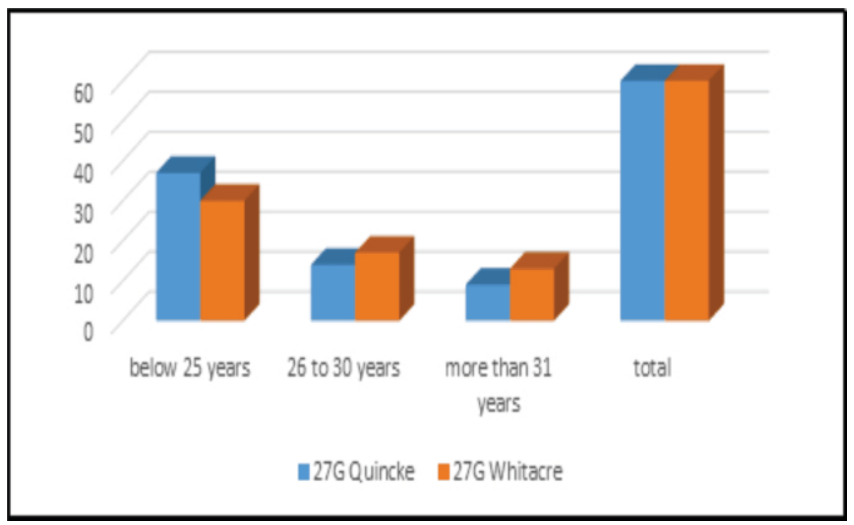

Figure 1. Age distribution between both the groups

Table 1. Incidence of headache after anesthesia between both the groups

\begin{tabular}{lcccc}
\hline Group & No. of patients & $\begin{array}{c}\text { Having } \\
\text { headache }\end{array}$ & Percentage & $p$-value \\
\hline Group A & 60 & 5 & $8.3 \%$ & 0.234 \\
$<25$ years & 37 & 1 & $2.7 \%$ & \\
26-30 years & 14 & 4 & $28.6 \%$ & \\
31-35 years & 09 & & nil & \\
Group B & 60 & 3 & $5 \%$ & \\
$<25$ years & 30 & 1 & $3.3 \%$ & \\
26-30 years & 17 & 2 & $11.8 \%$ & \\
31-35 years & 13 & & nil & \\
\hline
\end{tabular}

Table 2. Location, type, duration and onset of headache in different region

\begin{tabular}{lccc}
\hline & $\begin{array}{c}27 \text { G Quincke } \\
\text { (5 patients) }\end{array}$ & $\begin{array}{c}27 \text { G Whitacre } \\
\text { (3 patients) }\end{array}$ & $p$-value \\
\hline LOCATION & 3 & 1 & 0.27 \\
$\begin{array}{l}\text { Frontal } \\
\text { Occipital }\end{array}$ & & 1 & \\
$\begin{array}{l}\text { Generalized } \\
\text { TYPE }\end{array}$ & 2 & 1 & \\
Mild & 4 & 2 & 0.36 \\
$\begin{array}{l}\text { Moderate } \\
\text { Severe }\end{array}$ & 1 & 1 & \\
DURATION & & & \\
$<24$ hours & 3 & 3 & 0.13 \\
24 to 48 hours & 2 & 0 & \\
$>48$ hours & & & \\
ONSET & & & \\
$1^{\text {st }}$ day & & & \\
$2^{\text {nd }}$ day & 3 & & \\
$3^{\text {rd day }}$ & 1 & & \\
$4^{\text {th }}$ day & 1 & & \\
\hline
\end{tabular}

\section{DISCUSSION}

The selection of proper anesthesia for C-section relies on several factors like surgery prerequisite, level of urgency, status and desire of the patient. It is quiet common for patients to complain of headache after dural puncture. There exists ample amount of substantiation that PDPH occurs owing to a low CSF pressure ensuing due to CSF seepage through the dural puncture and also because of the incapability of choroid plexus to produce adequate fluid for maintaining CSF pressure. Furthermore, the negative pressure in the epidural space facilitates CSF withdrawal from subarachnoid space. CSF leakage further produces hypotension thus, producing intracranial venous dilatation and stemming up to increased brain volume at upright position. This creates a difference in CSF volume and pressure between the intracranial and intravertebral part of the subarachnoid space. The consequent venous dilation and compensatory rise in brain volume causes brain sag, employing traction and encouraging pain sensitive structures like dural vessels, basal dura and tentorium cerebelli, resulting in PDPH. Hence, it is observed that larger the number and size of holes in dura mater, CSF leakage would be more and prolonged time needed for repair and seal (approximately around two weeks). ${ }^{2}$ Reina MA et al (2000) documented lower incidence of PDPH with Whitacre needles owing to the tearing of collagen, developing inflammatory reaction causing significant edema and acting as a plug preventing CSF leakage. $^{8}$

PDPH contingent upon body posture gets aggravated while sitting or standing and comforted while lying down and is also related to the size, type of the spinal needle used. It is evident that pain is diminished gradually with the use of thinner, pencil tip needles, but the use of smaller needles (29G to $32 \mathrm{G}$ ) have 
shown inadequate success rates. These are correlated with multiple anesthesia attempts and high failure frequencies. However, the increased number of holes in the dura tend to upsurge the occurrence of headache and conquest the purpose of using a smaller gauge needle. ${ }^{3}$ Studies have shown that PDPH frequency ranges from 0 to $37.2 \%{ }^{9,10}$ Hence, it is concluded that thicker the needle (cutting type) more is the incidence of PDPH. ${ }^{11,12}$

In the present study, the incidence of PDPH was less $(5 \%$ in Whitacre group; 8.3\% Quincke group). These results clearly depicted reduced PDPH incidence while using 27G Whitacre needle instead of $27 \mathrm{G}$ Quincke needle (measured by the standardized questionnaire). Shah A et al (2002) ${ }^{2}$ and Santanen U et al (2004) $)^{5}$ showed that PDPH occurrence was much reduced with $27 \mathrm{G}$ Whitacre needles.

We observed that the location of headache was more constrained to the frontal area in case of Group A-Quincke needle when compared to Group B-Whitacre needle ( $p$-value 0.27 ) much less time in Group B ( $p$-value 0.13 ). However, the onset of PDPH (by $2^{\text {nd }}$ day in 2 patients) was seen to be in less number of patients receiving Whitacre needle anesthesia as compared to Quincke's needle ( $p$-value 0.44$)$. [Table 2]

Halpern S et al (1994) ${ }^{13}$, in their metaanalyses, concluded that a non-cutting small gauge needle should be used for high risk PDPH patients. Ghosh S et al (2016) ${ }^{14}$ in their study, observed lesser incidence of PDPH after using $25 \mathrm{G}$ Whitacre needle.

Cote $\mathrm{S}$ et al $(1991)^{15}$ found a higher incidence of PDPH in women $(16 \%)$ and in patients $<40$ years $(19.6 \%)$. This is the only study demonstrating an effect of age and sex on the incidence of PDPH, using a $27 \mathrm{G}$ needle.

Corbey MP et al (1997) ${ }^{16}$ observed a PDPH incidence of $0 \%$ with 27-G Whitacre needle and 5.6\% with 27-G Quincke needle $(\mathrm{P}=0.05)$. Usmani $\mathrm{S}$ et al $(2016)^{3}$ documented that Whitacre needles were more efficacious and produced less PDPH when compared to Quincke needles.

According to contemporary studies, frequency of PDPH after SA with 27-G spinal needle ranges from 0 to $9.3 \%$ and even up to $20.4 \%$ in female patients. ${ }^{17}$ These extraordinarily inconstant incidence rates insinuate indistinctness in expressing the PDPH criteria. Hence, an exceptional number of patients with non-specific post-operative headache could have been incorporated in the study group and considered having PDPH.

In the present study, it was seen that the incidence of PDPH was almost nil amongst older aged females (31-35 years) (Table 1) for both the Groups. This can be supported by Ahsan S et al (1996), who stated that there appeared to be a decreased incidence of PDPH with advancing age. ${ }^{18}$

27-G spinal needles were used here owing to the various technical difficulties linked with the use of $29 \mathrm{G}$ spinal needles, like reduced CSF flow rate, leading to greater propensity of anesthetic failure. ${ }^{19,20,21}$ Eriksson and coworkers
(1998) demonstrated that Whitacre needles poses less technical difficulties, rarer multiple punctures of the skin and dura, and less failure of blocks than cutting spinal needles. The application of 27-G Whitacre and 27-G Quincke spinal needles permitted prompt recognition of CSF after dural puncture due to a suction effect of the stylet. ${ }^{22}$ Some of the disadvantages of 27-G Quincke spinal needles include slower CSF flow recognition, longer injection time, bad flow of anesthetic, decreased resistance at injection site as when compared to 27-G Whitacre needles portraying an increased success rate of SA. ${ }^{22,23,24}$

\section{CONCLUSION}

It could be clearly indicated from this study, that $27-\mathrm{G}$ Whitacre spinal needles produces fewer cases of PDPH. ${ }^{5}$ The high incidence of non-specific post-operative headache could also relate to dehydration, abstention from food, hypoglycemia, caffeine deficiency, anxiety and immobilization leading to muscle tension. An optimum spinal needle should instigate minimum incidence of PDPH to facilitate the clinician in distinguishing the intrathecal space with precision and inject the LA safely. Hence, it can be suggested that routine use of 27-G Whitacre spinal needle should be practiced for greater patient satisfaction.

\section{REFERENCES}

1. Montasser MG. Post dural puncture headache after spinal anesthesia for caesarean section: A comparison of $27 \mathrm{G}$ Quincke and Whitacre spinal needles in midline and paramedian approaches. J Med Sci. 2015;15(1):44-49.

2. Shah A, Bhatia PK, Tulsiani KL. Post-dural puncture headache in Caesarean Section-a comparative study using $25 \mathrm{~g}$ Quincke, $27 \mathrm{~g}$ Quincke and $27 \mathrm{~g}$ Whitacre needle. Indian J Anaesthe. 2002;46(5):373-77.

3. Usmani S, Azmat J, Jameel S, Sirajuddin. Post dural puncture headache after spinal anaesthesia and chance of spinal failure: A comparative study using $23 \mathrm{G}$ Quincke, 25G Quincke, and $25 \mathrm{G}$ Whitacre needle. IOSR Journal of Dental and Medical Sciences. 2016;15(7):67-71.

4. Plewa MC, McAllister RK. Postdural Puncture Headache. 2021 Feb 3. In: StatPearls [Internet]. Treasure Island (FL): StatPearls Publishing; 2021 Jan-.

5. Santanen U, Rautoma P, Luurila H, Erkola O, Pere P. Comparison of 27-gauge $(0.41-\mathrm{mm})$ Whitacre and Quincke spinal needles with respect to post-dural puncture headache and non-dural puncture headache. Acta Anaesthesiol Scand. 2004 Apr;48(4):474-9.

6. Morewood GH. A rational approach to the cause, prevention and treatment of post-dural puncture headache. CMAJ. 1993;149(8):1087-93. 
7. Mowafy SMS, Abd Ellatif SE. Transcranial Doppler role in prediction of post-dural puncture headache in parturients undergoing elective cesarean section: prospective observational study. J Anesth. 2019;33(3):426-34.

8. Reina MA, Leon-Casasola OA, LopezA, Andres JD, Maartin S, Mora M. An in vitro study of dural lesions produced by $25-$ Gauge Quincke and Whitacre needles evaluated by scanning electron microscopy. Regional Anesthesia and Pain Medicine. 2000;25(4):393-02.

9. Shutt LE, Valentine SJ, Wee MYK, Page RJ, Prosser A, Thomas TA. Spinal anaesthesia for caesarean section. Comparison of 22 gauge and 25 gauge Whitacre needle with 26 gauge quincke needles. Br J Anaesth. 1992;69:589-94.

10. Flaatten H, Reader J. Spinal anaesthesia for out-patient surgery. Anaesthesia. 1985;40(11):1108-11.

11. Vandam LD, Dripps RD. Long term follow-up of patients who received 10,098 spinal anesthetics. Syndrome of decreased intracranial pressure (headache and occular and auditory difficulties). JAm Med Assoc. 1956;161(7):586-91.

12. Kaukinen S, Kaukinen L, Kannisto K, Kataja M. The prevention of headache following spinal anaesthesia. Ann Chir Gynaecol. 1981;70(3):107-11.

13. Halpern S, Preston R. Postdural puncture headache and spinal needle design. Metaanalyses. Anesthesiology.1994;81(6): 1376-83.

14. Ghosh S, Nayak SK, Roy S. Assessment of post dural puncture headache in patients undergoing caesarean section: A Comparison between 25 G Quinke v/s Whitacre needles. BR J Med Med Res. 2017;19(9):1-7.

15. Cote S, Socci M, Wiesel S. Spinal anesthesia with the 27 gauge needle. Can J Anaesth. 1991;38:A46.

16. Corbey MP, Bach AB, Lech K, Frarup AM. Grading of severity of post-dural puncture headache after 27-gauge Quincke and Whitacre needles. Acta Anaesthesiol Scand. 1997;41:779-84.

17. Despond O, Meuret P, Hemmings G. Postdural puncture headache after spinal anaesthesia in young orthopaedic outpatients using 27-g needles. Can J Anaesth. 1998;45:1106-9.

18. Ahsan S, Kitchen N, Jenkins C, Margary J. Incidence of postdural puncture headache following spinal anaesthesia for lower segment caesarean section with the 25 gauge polymedic spinal needle. J Pak Med Assoc. 1996;46(12):278-81.

19. Flaatten H, Rodt SA, Koller ME. Postdural puncture headache, A comparison between 26- and 29-Gauge needles in young patients. Anaesthesia. 1989;44:147-9.

20. Geurts JW, Haanschoten MC, van Wijk RM, Kraak H, Besse TC. Post-dural puncture headache in young patients. A comparative study between the use of $0.52 \mathrm{~mm}$ (25-gauge) and $0.33 \mathrm{~mm}$ (29-gauge) spinal needles. Acta Anaesthesiol Scand. 1990;34:350-3.
21. Abouleish E, Mitchell M, Taylor G, Miller H, Warters D, Rashad N. Comparative flow rates of saline in commonly used spinal needles including pencil-tip needles. Reg Anesth. 1994;19: 34-42.

22. Carson DF, Serpell MG. Clinical characteristics of commonly used spinal needles. Anaesthesia. 1995;50:523-5.

23. Lynch J, Kasper SM, Strick K, et al. The use of Quincke and Whitacre 27-gauge needles in orthopedic patients: incidence of failed spinal anesthesia and postdural puncture headache. Anesth Analg. 1994;79:124-8.

24. Mayer DC, Quance D, Weeks SK. Headache after spinal anesthesia for cesarean section. a comparison of the 27-gauge Quincke and 24-gauge Sprotte needles. Anesth Analg. 1992; 75:377-80. 